\title{
The Effect and Mechanism of Vascular Endothelial Growth Fac- tor (VEGF) on Tumor Angiogenesis in Gallbladder Carcinoma
}

\author{
Dongqing $X U^{1}$, Jianwen $L I^{1}$, Fangfang JIANG ${ }^{2}$, Kaishuang $C A I^{1}$, *Guangxue REN ${ }^{1}$ \\ 1. Department of Surgery (1), Yiling Hospital of Yichang, Yichang 443100, P.R. China \\ 2. Department of Surgery (II), Yiling Hospital of Yichang, Yichang 443100, P.R. China \\ *Corresponding Author: Email: rpzq8j@163.com
}

(Received 14 Jul 2018; accepted 10 Sep 2018)

\begin{abstract}
Background: To investigate the effect of vascular endothelial growth factor (VEGF) on tumor angiogenesis in gallbladder carcinoma.

Methods: Fifty one patients with gallbladder carcinoma were enrolled as observation group. Thirty healthy people were included as control group. Chemically synthesized siRNA sequences targeting VEGF was transfected with VEGF-siRNA. A blank group (group B), a negative control group (transfected with independent sequence, group C), and an inhibition group (transfected with VEGF siRNA, group D) were established. Physiological saline was set as group A. The expression of VEGF was detected by qRT-PCR. The expression of VEGF protein was detected by Western blot. MVD was used to measure microvessel density. CCK-8, Transwell and flow cytometry were used to detect cell proliferation, invasion and apoptosis.

Results: The tumor volume of nude mice and VEGF mRNA expression in group D was significantly smaller than that in group $\mathrm{B}$ and $\mathrm{C}(P<0.05)$. The MVD density in group $\mathrm{B}$ and $\mathrm{C}$ was significantly higher than that in group $\mathrm{D}(P<0.01)$. The proliferation of cells was detected from the 3 rd day, and the proliferation of cells in the blank and negative control groups was faster than that of the inhibition group $(P<0.05)$. The apoptosis rate of the blank group and the negative control group was lower than that of the inhibition group $(P<0.001)$.

Conclusion: VEGF is highly expressed in serum of patients with cholangiocarcinoma, it promotes angiogenesis, proliferation and invasion of gallbladder cancer cells, and inhibits apoptosis of tumor cells.
\end{abstract}

Keywords: Vascular endothelial growth factor; Gallbladder carcinoma; Angiogenesis; GBC-SD cells; Apoptosis

\section{Introduction}

Carcinoma of gallbladder is one of the most common and most malignant tumors of the biliary system. Its incidence has increased from 7 th to 5 th in the bowel tumors at the end of the 20 th century $(1,2)$. The incidence of gallbladder cancer has increased significantly, and it is on the rise (3). The early stage of the disease is very similar to the symptoms of cholecystitis, so early diagnosis is more difficult (4). This has seriously affected the quality of life of patients and caused a great economic and spiritual burden on the patient's families (5).

Vascular endothelial growth factor (VEGF) is highly specific. VEGF has high expression in many kinds of tumors (6-8). Tumor angiogenesis is a very complicated process. Because the structure and function of neovascularization in tumor tissue are imperfect, leakage is easy to occur. Once there is leakage, there is a great threat to the patient's life (9). 
VEGF is expressed in gallbladder carcinoma but has not been studied further (10). Therefore, in this study, we conducted an evidence-based study on the role of VEGF in angiogenesis of gallbladder carcinoma and provided a more scientific basis for clinical treatment.

\section{Materials and Methods}

\section{Clinical data of patients}

Fifty one patients with gallbladder cancer diagnosed after surgery in Yiling Hospital of Yichang, Yichang, China were enrolled as observation group. There were 20 male patients and $31 \mathrm{fe}-$ male patients with an average age of $62.21 \pm 6.25$ years. There were 44 patients with lymph node metastasis, 7 without lymph nodes metastasis, 40 patients with distant metastases, 11 patients without distant metastases. TNM staging: 9 patients with stage I+II, 42 patients with stage $\mathrm{III}+\mathrm{IV}, 30$ patients were poorly differentiated, and 21 patients were moderately and highly differentiated.

Thirty healthy people who underwent physical examination in our hospital without abnormal indicators were used as the control group. There was no statistically significant difference in gender and age between the two groups.

\section{Inclusion and exclusion criteria}

Inclusion criteria: Patients and family members were informed and signed informed consent. All patients met the American Joint Committee on Cancer 8th Edition TNM classification, and patients were older than 18 years.

Exclusion criteria: Patients with other malignant tumors, patients undergoing radiotherapy and chemotherapy before admission, patients with severe heart, brain, lung, kidney, liver function defects.

\section{Animal sources}

Sixteen BALB-C nude mice were purchased from Shanghai Slack Animal Laboratory, male, 4-5 weeks, weighing 25-30 g. They were randomly divided into groups $\mathrm{A}, \mathrm{B}, \mathrm{C}$, and $\mathrm{D}$, and each group had 4 nude mice. The mice were housed in separate cages at room temperature and had sufficient sunlight before being modeled. The noise was kept for less than 45 decibels and the mice were fed for one week.

\section{Construction of Gallbladder Carcinoma Nude Mice Model}

Nude mice in group A were injected with equal doses of normal saline. Group B was injected with cells from the blank group. Group C was injected with cells from the negative control group. Group D was injected with cells from the inhibition group and injected every other day after each injection, a total of 3 injections. Then the tumor size was measured every 5 days (long axis $\mathrm{L}$, short axis $\mathrm{W}$, volume $=1 / 2^{*} \mathrm{~L}^{*} \mathrm{~W} 2$ ) to draw the growth curve. After 30 days, the nude mice were sacrificed, and tumors were taken from group B, C, and D for experiment. The gallbladder tissue of nude mice in group A was used for experiments. The rest was stored with liquid nitrogen. siRNA was constructed according to the literature of Elbashir et al (11) and synthesized by Shanghai Genepharma.

\section{Detection of VEGF Expression in Nude} Mice Tissues and Cells by $q R T-P C R$

Total RNA was extracted using TRIzol reagent. cDNA extraction was performed according to the cDNA Synthesis Kit following the Kit instructions for reverse transcription. VEGF upstream primer: 5'-ATTTTTGTCTCATCCC-3', downstream primer: 5'-GGTCACTACTTGCTCCTCGTCG-3', RT-PCR kit was used to configure reaction system: $2.50 \mu \mathrm{L}$ cDNA template, upstream and downstream primers $0.5 \mu \mathrm{L}, 2.50 \mu \mathrm{L}$ dNTPmix, $10 *$ PCR buffer, $1.50 \mu \mathrm{L} \mathrm{MgCl} 2$, finally made up to $20 \mu \mathrm{L}$ using ddH2O. The PCR conditions were as follows: predenaturation at $95^{\circ} \mathrm{C}$ for 5 minutes, $95^{\circ} \mathrm{C}$ for $30 \mathrm{~s}, 65^{\circ} \mathrm{C}$ for $45 \mathrm{~s}$, and $72^{\circ} \mathrm{C}$ for $30 \mathrm{~s}$ for 40 cycles. U6 was used as the reference gene 5'-CTCGCTTCGGCAGCACA-3'5'AACGCT'TCACGAATT'TGCGT-3. '. The resulting expression was calculated using the $2-\Delta \mathrm{Ct}$ method. 
Western Blot Detection of VEGF Protein Expression in Nude Mice

Fifty $\mathrm{mg}$ gallbladder tissue was smashed, homogenized and digested with $1.5 \mathrm{~mL} 0.25$ trypsin. The cells were lysed using RIPA lysate. Using $12 \%$ SDS-PAGE gel electrophoresis, the protein was electrotransfered to PVDF membrane. The membrane was placed in 5\% skim milk blocked at $4{ }^{\circ} \mathrm{C}$ overnight, washed with TBST, added nude mouse anti-human VEGF monoclonal antibody (1: 400), incubated at room temperature for $2 \mathrm{~h}$; washed again with TBST, added horseradish peroxidase-conjugated goat anti-rabbit secondary antibody, incubated for $1 \mathrm{~h}$ at room temperature, washed with TBST, and developed color. GAPDH was used as an internal control. Protein bands were used to measure the gray level of the protein bands using the Quantity one software. Product relative expression $=$ target protein/internal control bands were grayscale.

\section{MVD determination}

MVD was detected by CD34 immunohistochemical staining of the gallbladder tissue of two groups of nude mice by SABC method. The detection method was performed according to the manufacturer's instructions (12). The MVD was counted, and a brown endothelial cell or cell groups distinct from the background was considered as a single microvessel. 5 slices were counted and the average was taking as the result.

\section{CCK-8 detection of cell proliferation}

In the blank group, negative control group and inhibition group, $1 * 106$ GBC-SD cells were transfected for $24 \mathrm{~h}$, and the transfected GBCSD cells were then cultured in 96-well culture plates for $4 \mathrm{~h}$ at $6 \times 103$ /well. $10 \mu \mathrm{L}$ of CCK-8 test solution was added daily. The plate reader was used to measure at $450 \mathrm{~nm}$ wavelength.

\section{Transwell detection of cell invasion}

The transfected cells were selected to be made into a suspension and inoculated into the upper chamber, $4 * 104$ cells per well, and cultured in RPMI-1640 medium (without FBS) for $24 \mathrm{~h}$, and the RPMI-1640 medium was replaced (without
FBS). Subsequently, $400 \mu \mathrm{L}$ of $20 \%$ FBS RPMI1640 medium was added to the lower chamber, and the cells were incubated for $36 \mathrm{~h}$. A sterile cotton swab was used to wipe off the unpenetratized cells attached to the inner surface of the membrane and fixed with formaldehyde. Crystal violet $(0.1 \%)$ staining was performed under a light microscope, and 6 replicate wells were set in the experiment and repeated 3 times.

\section{Flow Cytometry Apoptosis}

The transfected cells was digested with $0.25 \%$ trypsin. The cell concentration was adjusted to $1 * 105 / \mathrm{mL}$. Annexin V-FITC kit was used to perform count analysis on a flow cytometer (Beckman-CytoFLEX) and repeated 3 times.

\section{Elisa detection}

Fifty $\mu \mathrm{L}$ of standard solution of different concentrations was separately added to the collected serum in the blank microwell. $50 \mu \mathrm{L}$ of distilled water was added to the blank control well. Fifty $\mu \mathrm{L}$ of antibody was added; $40 \mu \mathrm{L}$ of the sample was added to the remaining microwells followed by $10 \mu \mathrm{L}$ of the biotinylated antibody. Subsequently, the plate was incubated at $37{ }^{\circ} \mathrm{C}$ for 30 min. Fifty $\mu \mathrm{L}$ of the enzyme standard solution was added to each well. Incubate at $37^{\circ} \mathrm{C}$ for 60 min, wash the plate again for 5 times. Add horseradish peroxidase labeled $100 \mu \mathrm{L} /$ well sealing plate, incubate at $37^{\circ} \mathrm{C}$ for $15 \mathrm{~min}$ in the dark. Color substrate TMB was added and the microplate reader was used for detection within $15 \mathrm{~min}$ to determine the maximum absorption wavelength of $450 \mathrm{~nm}$. Set 3 sets of duplicate wells and repeat the experiment 3 times.

\section{Statistical analysis}

We used the SPSS20.0 software package (Shanghai Cabit) for analysis, using GraphPad Prism 7 software for picture drawing; the enumeration data were expressed as rate (\%) and used the chi-square analysis; measurement data were expressed as the mean \pm standard deviation (Mean \pm SD) and used the $t$-test, and multiple groups were compared using analysis of variance. $P<0.05$ indicates that there is a statistically difference. 


\section{Ethics aspects}

This study was approved by the Ethics Committee of Yiling Hospital of Yichang. Patients and their families were informed in advance of the study, and singed an informed consent form.

\section{Results}

\section{Serum VEGF expression in patients}

The serum VEGF expression in the two groups was detected by ELISA method. The serum
VEGF expression in the control group was 142.64 $\pm 65.22 \mathrm{pg} / \mathrm{mL}$, while the serum VEGF expression in the observation group was $288.41 \pm 86.25 \mathrm{pg} / \mathrm{mL}$. There was a significant difference in the expression of VEGF in serum $(P<0.05)$. Further analysis of the relationship between VEGF and clinical data of the observation group found that VEGF showed significant differences in tumor differentiation, lymph node metastasis, distant metastasis and clinical stage $(P<0.01)$ (Table 1).

Table 1: Relationship between VEGF and clinical data

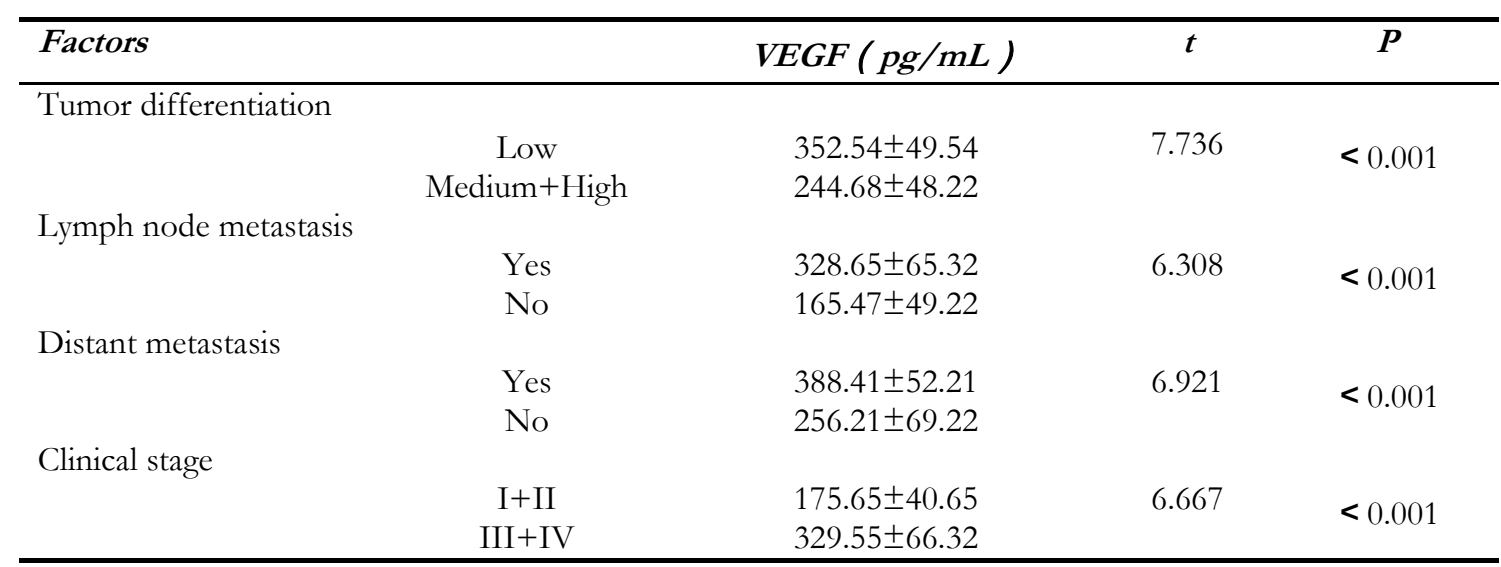

Tumor growth in nude mice in each group

We successfully constructed a gallbladder cancer tumor-bearing nude mouse model (the tumor tissues were identified for gallbladder cancer). During the modeling period, each group of nude mice grew well except one death in group B and group C. The tumor size of nude mice showed that group A had no tumors, and the tumor size of nude mice in group $B$ and group $C$ increased gradually with the increase of time, and there was no difference in tumor volume between the two groups. The tumor volume in group D also increased with time, but it was significantly smaller than that in group B and $\mathrm{C}(P<0.01)$ (Fig. 1).

\section{Expression of VEGF in Gallbladder Tissue and GBC-SD Cells}

We detected the relative expression of VEGF mRNA in GBC-SD and gallbladder tissues of nude mice by real-time fluorescence quantitative
PCR, and found that in the nude mouse model with successful modeling, and the relative expression of VEGF mRNA was statistically different among the groups of $\mathrm{A}, \mathrm{B}, \mathrm{C}$, and $\mathrm{D}(\mathrm{F}=8.731$, $P=0.024)$.

The relative expression of VEGF mRNA in group $\mathrm{A}$ was significantly lower than that in group $\mathrm{B}$ and $\mathrm{C}\left(P_{\mathrm{A} \text { vs } \mathrm{B}}=0.001, P_{\mathrm{A}}\right.$ vs $\left.\mathrm{C}=0.002\right)$. There was no significant difference in the relative expression of VEGF mRNA between the group $\mathrm{B}$ and $\mathrm{C}(P=0.186)$. The relative expression of VEGF mRNA in group $\mathrm{D}$ was significantly lower than that in group $\mathrm{B}$ and $\mathrm{C}\left(P_{\mathrm{D} \text { vs } \mathrm{B}}=0.013, P_{\mathrm{D} \text { vs }}\right.$ $\left.{ }_{C}=0.023\right)$. The relative expression of VEGF mRNA in group $D$ was significantly higher than that in group $A(P=0.047)$ (Fig. 2A). The relative expression of VEGF mRNA in each group of cells was also different $(\mathrm{F}=5.598, P=0.026)$. The relative expression of VEGF mRNA in the blank group and the negative control group was signifi- 
cantly higher than that in the inhibitory group $\left(P_{\text {Blank group vS Inhibitory group }}=0.019, P_{\text {Negative control group vS }}\right.$ Inhibitory group $=0.016)$. There was no difference in the relative expression of VEGF mRNA between the blank group and the negative control group $(P=0.921)$ (Fig. 2B).

\section{The relative expression of VEGF protein in nude mouse model}

We detected the relative expression of VEGF protein in gallbladder tissue of nude mice by Western Blot and found that the relative protein expression of VEGF in each group of A, B, C, and $\mathrm{D}$ was statistically different $(\mathrm{F}=25.800$, $P=0.000)$. Among them, relative expression of VEGF protein in group A was significantly lower than that in group $\mathrm{B}$ and $\mathrm{C}\left(P_{\mathrm{A} \text { vs } \mathrm{B}}<0.001, P_{\mathrm{A} \text { vs }}\right.$ $c<0.001)$.

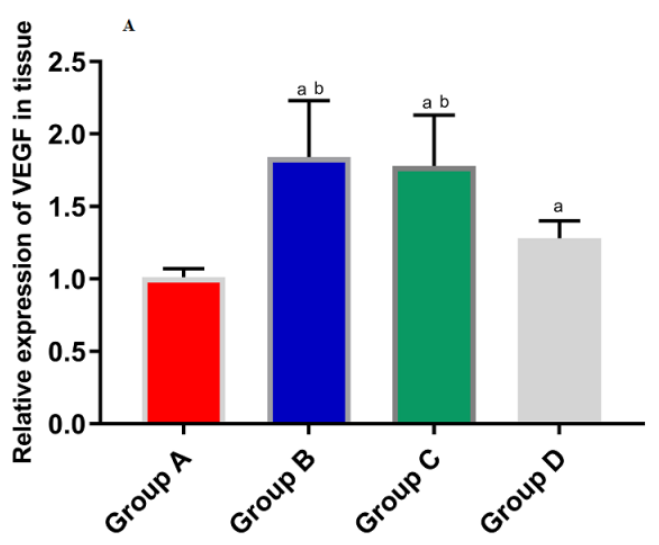

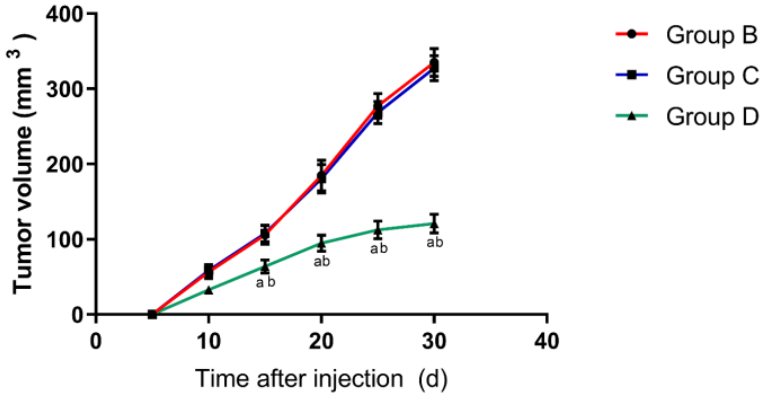

Fig. 1: Comparison of tumor volume in nude mice in each group

In group $\mathrm{A}$, there was no tumor in nude mice. The tumor volume of nude mice in group B and group C increased gradually with time, and there was no difference in tumor volume between the two groups. The tumor volume of group $\mathrm{D}$ also increased with time, but the tumor volume was less than in group B and C. a indicates that there is a difference compared with the group B, and $\mathrm{b}$ indicates a difference compared with the group $\mathrm{C}$

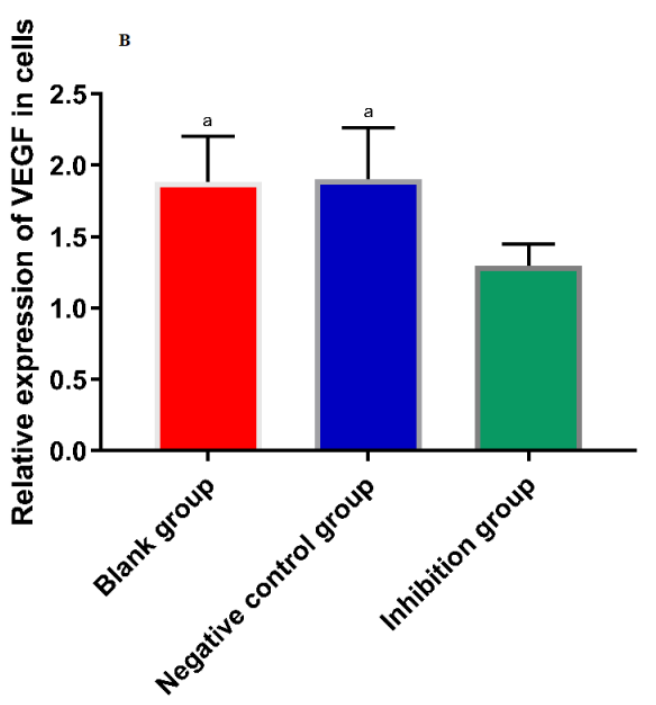

Fig. 2A: Expression of VEGF in tissues

The expression of VEGF and VEGF mRNA in gallbladder tissues of nude mice in each group was different. The expression of VEGF mRNA in group A was lower than that in group B and C. There was no difference in the expression of VEGF mRNA between group B and group C. The expression of VEGF mRNA in group D was significantly lower than that of group B and C. Compared with group A, there was a significant increase in the expression of VEGF mRNA in group D. a indicates that there is a difference compared with the group $\mathrm{B}$, and $\mathrm{b}$ indicates a dif-

ference compared with the group C

B: Expression of VEGF in cells

The expression of VEGF mRNA in each group was different. The relative expression of VEGF mRNA in the blank group and the negative control group was higher than that in the inhibition group, while there was no difference in the relative expression of VEGF mRNA between the blank group and the negative control group. a indicates that there is a difference compared with the inhibition group 
There was no significant difference in the expression of VEGF protein between group B and group $C(P=0.748)$. Relative expression of VEGF protein in group $\mathrm{D}$ was significantly lower than that in group $\mathrm{B}$ and $\mathrm{C}\left(\mathrm{P}_{\mathrm{D}}\right.$ vs ${ }_{\mathrm{B}}=0.004, \mathrm{P}_{\mathrm{D}}$ vs $\left.{ }_{C}=0.002\right)$. The relative protein expression of VEGF in group $\mathrm{D}$ was significantly higher than that in group $\mathrm{A}(P=0.003)$ (Fig. 3).

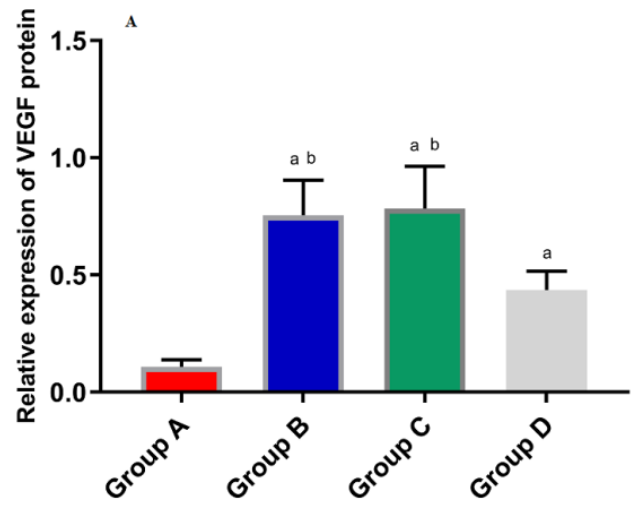

B

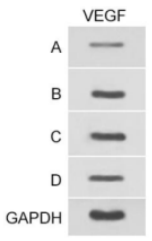

Fig. 3: The expression of VEGF protein in gallbladder tissue of each group

The relative expression of VEGF protein in gallbladder tissue of nude mice was detected by Western Blot. 3A: The expression of VEGF in each group was different. The relative expression of VEGF protein in group A was significantly lower than that of group B and C. There was no difference in the proportion of VEGF protein between group $\mathrm{B}$ and group $\mathrm{C}$. The expression of VEGF in group D was significantly lower than that of group B and C. Compared with group $\mathrm{A}$, the expression of VEGF increased in group D. a indicates that there is a difference compared with the A group, and $\mathrm{b}$ indicates a difference compared with the $\mathrm{D}$ group. 3B: Western Blotting protein map

\section{Nude mouse MVD situation}

After staining, we used an optical microscope to count the MVD of gallbladder tissue in 4 groups of nude mice. The results showed that there was a statistically significant difference in MVD counts among the 4 groups $(\mathrm{F}=17.069, P=0.000)$. The sparse MVD of the brown cords in group A was significantly lower than that in the other three groups ( $P_{\mathrm{A} \text { vs B }}<0.001, P_{\mathrm{A} \text { vs } \mathrm{C}}<0.001, P_{\mathrm{A}}$ vs $\left.{ }_{D}=0.036\right)$. The MVD density of cords in group $B$ and $\mathrm{C}$ was significantly higher compared with that in group $\mathrm{D}\left(\mathrm{P}_{\mathrm{B} \text { vs } \mathrm{D}}=0.002, \mathrm{P}_{\mathrm{C} \text { vs } \mathrm{D}}=0.001\right)$. There was no difference in MVD between group $\mathrm{B}$ and group $\mathrm{C}(P=0.758)$ (Table 2$)$.

\section{Cell proliferation}

We detected the proliferation of cells in each group by CCK- 8 method and found that there was a difference in the proliferation of cells from the 3rd day $(P<0.05)$. In the blank group and the negative control group, the proliferation rate of the cells was significantly faster than that of the inhibition group $(P<0.05)$, and there was no difference in the cell proliferation ability between the blank group and the negative control group. (Fig. 4).

\section{Cell invasion}

We detected the cells in each group by Transwell cell invasion assay and found that there were differences in cell invasion between the groups $(\mathrm{F}=19.509, P=0.001)$.

Table 2: MVD situation of nude mice

\begin{tabular}{lccc}
\hline Group & $\begin{array}{c}\text { MVD count } \\
\text { (cord) }\end{array}$ & $\boldsymbol{F}$ & $\boldsymbol{P}$ \\
\hline A $(\mathrm{n}=4)$ & $1.5 \pm 0.8$ & \\
$\mathrm{~B}(\mathrm{n}=4)$ & $15.6 \pm 4.6 \mathrm{ab}$ & & \\
$\mathrm{C}(\mathrm{n}=4)$ & $16.4 \pm 5.1 \mathrm{ab}$ & 17.069 & 0.000 \\
$\mathrm{D}(\mathrm{n}=4)$ & $5.5 \pm 1.9 \mathrm{a}$ & & \\
Note: a indicates a difference compared with group A \\
$(P<0.05)$, b indicates a statistical difference with group D \\
$(P<0.05)$
\end{tabular}




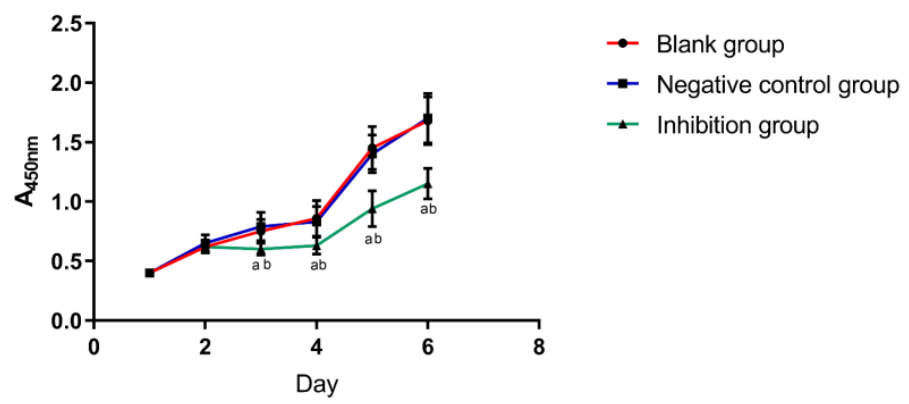

Fig. 4: Growth of cells in each group

We detected by CCK-8 method that the proliferation of cells in each group was different from the 3rd day. The proliferation of cells in the blank group and the negative control group was faster than that in the inhibition group, there was no difference in cell proliferation ability between the blank group and the negative control group a indicates a difference compared with the blank group, and $\mathrm{b}$ indicates a difference compared with the negative control group

The number of permeated cells in the blank group and the negative control group was significantly higher than that in the inhibition group $\left(P_{\text {Blank group VS Inhibitory group }}<0.001, P_{\text {Negative control group VS }}\right.$
Inhibitory group $=0.001)$, but there was no difference in the number of cell permeation between the blank group and the negative control group $(P=0.505)$ (Table 3).

Table 3: Invasion of GBC-SD cells after transfection

\begin{tabular}{lccc}
\hline Group & $\begin{array}{c}\text { Number of cell } \\
\text { permeation }\end{array}$ & $\boldsymbol{F}$ & $\boldsymbol{P}$ \\
\hline Blank (n=4) & $115.54 \pm 13.68$ & & \\
& & 19.509 & 0.001 \\
Negative control (n=4) & $109.82 \pm 12.27 \mathrm{a}$ & & \\
Inhibition (n=4) & $68.38 \pm 8.35 \mathrm{a}$ & & \\
\hline
\end{tabular}

Note: a indicates a difference compared with the blank group $(P<0.05)$

\section{Apoptosis}

We detected the apoptosis of cells in each group on the 6th day by flow cytometry and found that there was a difference in apoptosis between the groups $(\mathrm{F}=15.571, P=0.001)$. The apoptosis rate of the blank group and the negative control group was significantly lower than that of the inhibition group ( $P_{\text {Blank group vs Inhibitory group }}=0.001, P_{\text {Nega- }}$ tive control group vs Inhibitory group $=0.001)$. There was no difference in the apoptosis rate between the blank group and the negative control group $(P=0.878)$.

\section{Discussion}

Gallbladder cancer occurs mostly in the elderly over the age of 60, and the incidence of men is lower than that of women. Gallbladder carcino- ma is characterized by high degree of malignancy, rapid infiltration and easy transfer, resulting in low surgical resection rate and multiple cleanings after resection (13). The occurrence and development of gallbladder cancer is regulated by many factors, among which apoptosis and proliferation disorders and tumor angiogenesis are closely related to its biological behavior $(14,15)$. Therefore, finding a way to prevent the occurrence, development and infiltration of gallbladder cancer has become the focus of attention today. VEGF is the most effective pro-angiogenic factor nowadays, which binds to flt-1 and flt$1 / \mathrm{KDR}$ in a paracrine manner (16). The regulation of VEGF by miR-205 had a significant role in promoting the invasion of human ovarian cancer (17). Down regulation of VEGF had an inhibitory effect on lung cancer cell proliferation 
(18). However, there are few literatures related to the regulation of VEGF in gallbladder carcinoma. In this study, the expression of VEGF in the serum of the observation group was significantly higher than that of the control group, and the expression of VEGF was shown in another (19). MVD was significantly reduced in nude mice by inhibiting the expression of VEGF, indicating that VEGF expression is directly or indirectly associated with microvascular angiogenesis.

The cell proliferation ability of the blank group and the negative control group was significantly higher than that of the inhibition group. The number of cell permeation in the inhibition group was significantly lower than that in the other two groups. Finally, we found that inhibition of VEGF expression can effectively promote apoptosis. Inhibiting the expression of VEGF by targeting can inhibit the proliferation and migration of gastric cancer cells and promote the apoptosis of gastric cancer cells (20).

However, our current study still had some limitations. Firstly, this study did not detect VEGF expression in human tissues as an in vitro study, and the small number of our samples did not illustrate the accuracy of this study. Secondly, we did not dig deep into the mechanism of VEGF in gallbladder cancer. We hope to conduct clinical trials in future studies which will further verify the accuracy of our experiments.

\section{Conclusion}

VEGF plays an important role in the promotion of angiogenesis in gallbladder carcinoma, promotes the proliferation, invasion, and apoptosis of tumor cells, and is expected to serve as a potential diagnostic indicator.

\section{Ethical considerations}

Ethical issues (Including plagiarism, informed consent, misconduct, data fabrication and/or falsification, double publication and/or submission, redundancy, etc.) have been completely observed by the authors.

\section{Acknowledgements}

We received no funding support for this study.

\section{Conflict of interest}

The authors declare that there is no conflict of interest.

\section{References}

1. Donohue JH, Stewart AK, Menck HR (1998). The National Cancer Data Base report on carcinoma of the gallbladder, 1989-1995. Cancer, 83: 2618-2628.

2. Ma PX, Zhang R (1999). Synthetic nano-scale fibrous extracellular matrix. J Biomed Mater Res, 46: 60-72.

3. Muething L, Burton JR (2017). Malignancy and Primary Sclerosing Cholangitis: Cholangiocarcinoma, Hepatocellular Carcinoma, and Gallbladder Carcinoma. Primary Sclerosing Cholangitis. Springer, Cham, 13-27.

4. Martins-Filho ED, Batista TP, Kreimer F, Martins AC, Iwanaga TC, Leao Cde S (2015). Prevalence of incidental gallbladder cancer in a tertiary-care hospital from pernambuco, Brazil. Arq Gastroenterol, 52: 247-249.

5. Goyal G, Narayan KS, Gupta GK, Nijhawan S (2017). Carcinoma of gallbladder: Clinical evaluation and survival rate at a tertiary care center in Rajasthan. Indian J Gastroenterol, 36: 326-26.

6. Ferrara N, Adamis AP (2016). Ten years of antivascular endothelial growth factor therapy. Nat Rev Drug Discov, 15: 385-403.

7. Zang J, Hu Y, Xu X, Ni J, Yan D, Liu S, He J, Xue J, Wu J, Feng J (2017). Elevated serum levels of vascular endothelial growth factor predict a poor prognosis of platinum-based chemotherapy in non-small cell lung cancer. Onco Targets Ther, 10: 409-415.

8. Zakraoui $\mathrm{O}$, Marcinkiewicz $\mathrm{C}$, Aloui $\mathrm{Z}$ et al (2017). Lebein, a snake venom disintegrin, suppresses human colon cancer cells proliferation and tumor-induced angiogenesis through cell cycle arrest, apoptosis induction and inhibition of VEGF expression. Mol Carcinog, 56: 18-35. 
9. Giatromanolaki A, Koukourakis MI, Simopoulos C, Polychronidis A, Sivridis E (2003). Vascular endothelial growth factor (VEGF) expression in operable gallbladder carcinomas. EurJ Sung Oncol, 29: 879-883.

10. Jin YP, Hu YP, Wu XS et al (2018). miR-143-3p targeting of ITGA6 suppresses tumour growth and angiogenesis by downregulating PLGF expression via the PI3K/AKT pathway in gallbladder carcinoma. Cell Death Dis, 9: 182.

11. Elbashir SM, Harborth J, Lendeckel W, Yalcin A, Weber K, Tuschl T (2001). Duplexes of 21-nucleotide RNAs mediate RNA interference in cultured mammalian cells. Nature, 411: 494-498.

12. Chuanliang $P$, Yunpeng $Z$, Yingtao H, Qifeng $S$, Xiaogang Z, Bo C (2016). Syk expression in non-small-cell lung cancer and its relation with angiogenesis. J Cancer Res Ther, 12: 663666.

13. Meyerhardt JA, Zhu AX, Stuart K et al (2008). Phase-II study of gemcitabine and cisplatin in patients with metastatic biliary and gallbladder cancer. Dig Dis Sci, 53: 564-570.

14. Sun KK, Hu PP, Xu F (2018). Prognostic significance of long non-coding RNA MALAT1 for predicting the recurrence and metastasis of gallbladder cancer and its effect on cell proliferation, migration, invasion, and apoptosis. J Cell Biochem, 119: 3099-3110.
15. McFadden PM, Krementz ET, McKinnon WM, Pararo LL, Ryan RF (1979). Metastatic melanoma of the gallbladder. Cancer, 44: 18021808.

16. Picard A, Boscolo E, Khan ZA, Bartch TC, Mulliken JB, Vazquez MP, Bischoff J (2008). IGF-2 and FLT-1/VEGF-R1 mRNA levels reveal distinctions and similarities between congenital and common infantile hemangioma. Pediatr Res, 63: 263-267.

17. Li J, Li L, Li Z, Gong G, Chen P, Liu H, Wang J, Liu Y, Wu X (2015). The role of miR-205 in the VEGF-mediated promotion of human ovarian cancer cell invasion. Gynecol Oncol, 137: 125-133.

18. Kim JH, Kim MS, Lee BH et al (2017). Marmesin-mediated suppression of VEGF/VEGFR and integrin beta1 expression: Its implication in non-small cell lung cancer cell responses and tumor angiogenesis. Oncol Rep, 37: 91-97.

19. Liu MC, Jiang L, Hong HJ, Meng ZW, Du Q, Zhou LY, She FF, Chen YL (2015). Serum vascular endothelial growth factors $\mathrm{C}$ and $\mathrm{D}$ as forecast tools for patients with gallbladder carcinoma. Tumour Biol, 36: 6305-6312.

20. Liu K, Chen H, You Q, Shi H, Wang Z (2014). The siRNA cocktail targeting VEGF and HER2 inhibition on the proliferation and induced apoptosis of gastric cancer cell. Mol Cell Biochem, 386: 117-124. 